\title{
Tumor de parótida bilateral y múltiple
}

\author{
Wally Joel Reynoso Heinsenª, Paolo Ciardoa, Jazmín Guevara Laraa, José Luis Gómez \\ Rodrígueza ${ }^{\mathrm{a}}$ José Ignacio Jaén Díaz ${ }^{\mathrm{b}}$ y Blanca Cordero García ${ }^{\mathrm{c}}$
}

\author{
${ }^{a}$ M.I.R. de Medicina de Familia \\ y Comunitaria. Unidad Docente \\ Multiprofesional de Atención \\ Familiar y Comunitaria de \\ Toledo. España. \\ ${ }^{\mathrm{b}}$ Médico de Familia. Centro de \\ Salud de Buenavista. Toledo. \\ España. \\ ${ }^{\mathrm{C}}$ Médico de Familia. Centro \\ de Salud de Santa María de \\ Benquerencia. Toledo. España. \\ Correspondencia: \\ Wally Joel Reynoso Heinsen. \\ Correo electrónico: \\ wallyjrh@gmail.com.
}

Recibido el 10 de marzo de 2014.

Aceptado para su publicación el 23 de abril de 2014.

\section{RESUMEN}

Los tumores de las glándulas salivales, aunque poco frecuentes, pueden ser motivo de consulta en atención primaria. De todas, es la glándula parótida el sitio donde asientan con más frecuencia (80-85 \% de los casos), siendo el adenoma pleomorfo el más común, seguido del tumor de Warthin que representa entre el $2 \%$ y el $15 \%$ del total de las neoplasias benignas. Presentamos un caso de tumor de Warthin bilateral y multifocal detectado y diagnosticado, inicialmente, a través de la ecografía y de la punción-aspiración con aguja fina (PAAF) realizadas en el centro de salud de Buenavista, Toledo.

Palabras Clave: Neoplasias de las Glándulas Salivales. Tumor de Warthin. Ecografía.

\section{ABSTRACT}

\section{Bilateral and multiple parotid gland tumour}

Salivary gland tumours, although quite uncommon, may be a reason for primary care consultation. Of all the glands, the parotid gland is where they are most frequently located $(80-85 \%$ of cases), with the pleomorphic adenoma being the most common, followed by the Warthin tumour, which makes up between $2 \%$ and $15 \%$ of the total of benign neoplasms. We present the case of a bilateral multifocal Warthin tumour initially detected and diagnosed by ultrasound scan and fine needle puncture-aspiration assessment (PAAF), carried out at the Buenavista health centre, Toledo.

Key words: Salivary Gland Neoplasms. Warthin tumour. Ultrasonography.

\section{INTRODUCCIÓN}

Los tumores de las glándulas salivales constituyen un grupo heterogéneo de neoplasias que varían considerablemente según su origen anatómico, histológico y comportamiento biológico. Anatómicamente, la glándula parótida es la más frecuentemente afectada, con un $80-85 \%$ de los casos. Tres de cada cuatro lesiones parotídeas son benignas ${ }^{1}$.

Histológicamente, el tipo más común de los tumores benignos es el adenoma pleomórfico o tumor mixto (aproximadamente el 50 \%). Otros tumores benignos menos habituales son el adenoma de células basales, el adenoma canalicular y, sobre todo, el tumor de Warthin o cistoadenoma papilar linfomatoso o adenolinfoma, con un 2 al $15 \%$ de los casos ${ }^{1-3}$.

El tumor de Warthin predomina en varones (4:1), entre los 60 y 70 años, sobre todo fumadores; puede ser solitario o bilateral en el $10 \%$ de los casos y, en ocasiones, multifocal, de crecimiento lento y con posibilidad de malignizar$\mathrm{se}^{1-4}$. La transformación maligna se describe en solo el $0,1 \%$ de los casos, y por lo general se presenta en el epitelio linfoide ${ }^{1,5}$.

En cuanto a los tumores malignos, los más frecuentes son el carcinoma mucoepidermoide y el carcinoma adenoide quístico ${ }^{4}$. Otros tumores agresivos raros incluyen el carcinoma de células pequeñas primario y el carcinoma salival ductal, que es más frecuente en hombres mayores de 60 años ${ }^{1,3,5}$. 
Clínicamente, la mayoría de los pacientes con tumores de las glándulas salivales se presentan con una masa o hinchazón indolora. Signos o síntomas neurológicos, como la parálisis del nervio facial, casi siempre se relacionan con tumores malignos ${ }^{1-3}$.

De cara al diagnóstico, y dependiendo de la ubicación y el tamaño de la masa, la ecografía puede proporcionar una resolución de alta calidad y mostrar las características de los tejidos explorados; además, el ultrasonido puede facilitar la punción aspiración con aguja fina (PAAF). Tanto la tomografía computarizada (TAC) como la resonancia magnética (RMN) pueden ser necesarias para evaluar la extensión local, a hueso, perineural y metástasis en ganglios linfáticos. Para el diagnóstico definitivo se requiere una muestra de tejido.

El tratamiento consiste en cirugía parcial, subtotal o parotidectomía total, con preservación del nervio facial ${ }^{5}$.

\section{CASO CLÍNICO}

Se trata de un varón de 68 años, fumador de un paquete al día durante los últimos 40 años, sin alergias medicamentosas conocidas. No es hipertenso, ni diabético, ni tiene dislipemia. Intervenido de cataratas.

Nuestro paciente empezó a ser estudiado en medicina interna, un año antes, por ciatalgia y edemas en miembros inferiores de un mes de evolución. En la exploración clínica se palparon, casualmente, dos masas duras e indoloras en ambas paróti- das, motivo por el que se solicita una ecografía de dichas glándulas y una PAAF de las lesiones detectadas en ellas. Su médico de familia asumió la realización de ambas técnicas (ecografía y PAAF).

- Informe ecográfico: "A nivel del lóbulo superficial de la glándula parótida derecha se identifican dos lesiones nodulares hipoecogénicas de aspecto sólido, una más lateral de $32 \mathrm{~mm}$ y de bordes bien definidos y otra más medial y profunda de unos $38 \mathrm{~mm}$ (figura 1). A nivel del lóbulo superficial de la parótida izquierda se identifica una lesión nodular hipoecogénica y heterogénea (sólida/microquística), de contornos mamelonados y con microcalcificaciones en su interior, vascularizada y de unos $32 \mathrm{~mm}$ (figura 2)".

- Informe de las PAAFs:

- PAAF de área parotídea izquierda: citología negativa para células malignas, compatible con tumor de Warthin.

- PAAF de área parotídea derecha: citología negativa para células malignas, compatible con tumor de Warthin. (Bilateral).

- Informe de la Resonancia Magnética Nuclear: "Se observan múltiples lesiones nodulares heterogéneas, en ambas glándulas parótidas. Algunas de estas lesiones presenta áreas multiquísticas, con contenido hiperintenso, en relación con contenido proteináceo/hemático y todas ellas presentan un realce intenso. Compatible con tumor de Warthin multicéntrico y bilateral" (figura 3).

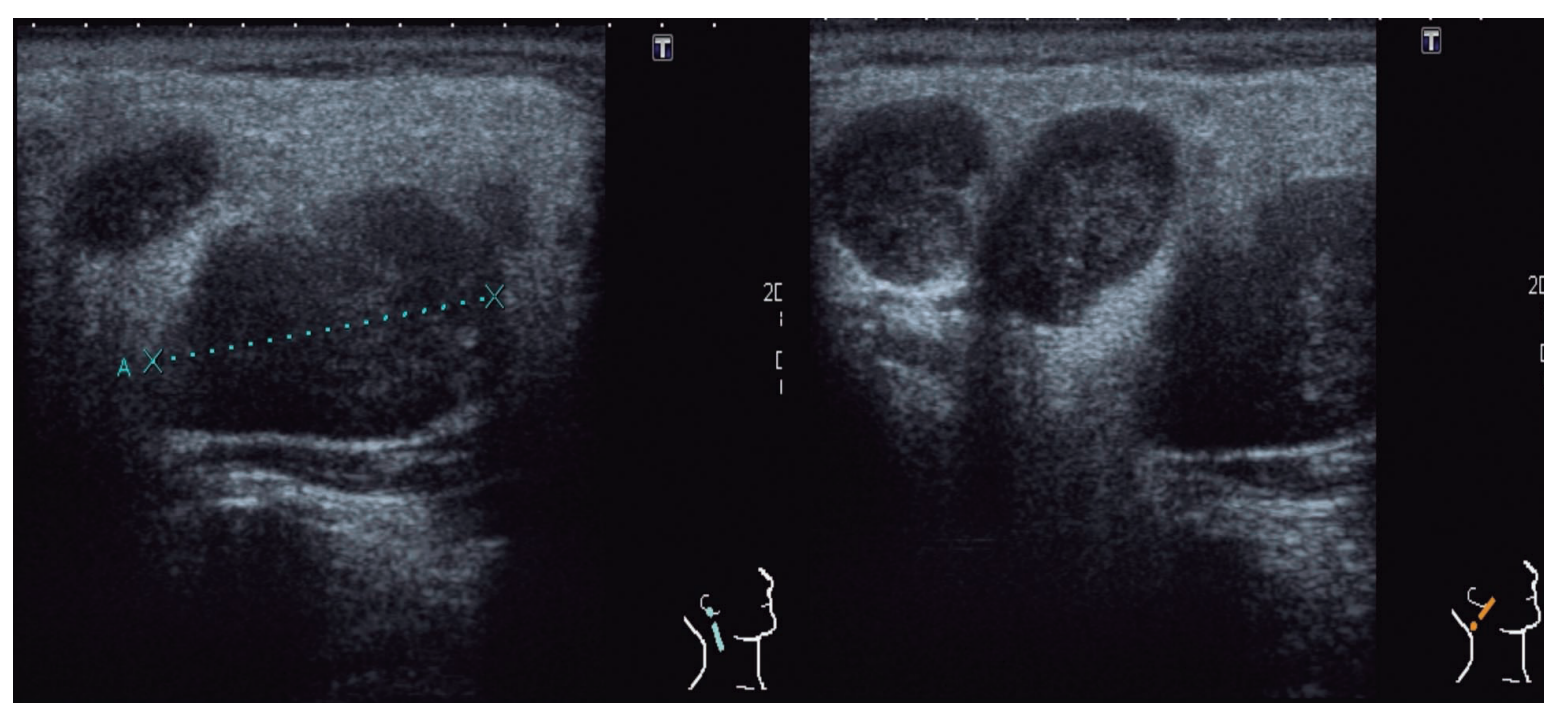

Figura 1. Corte ecográfico longitudinal y transversal de la glándula parótida derecha 


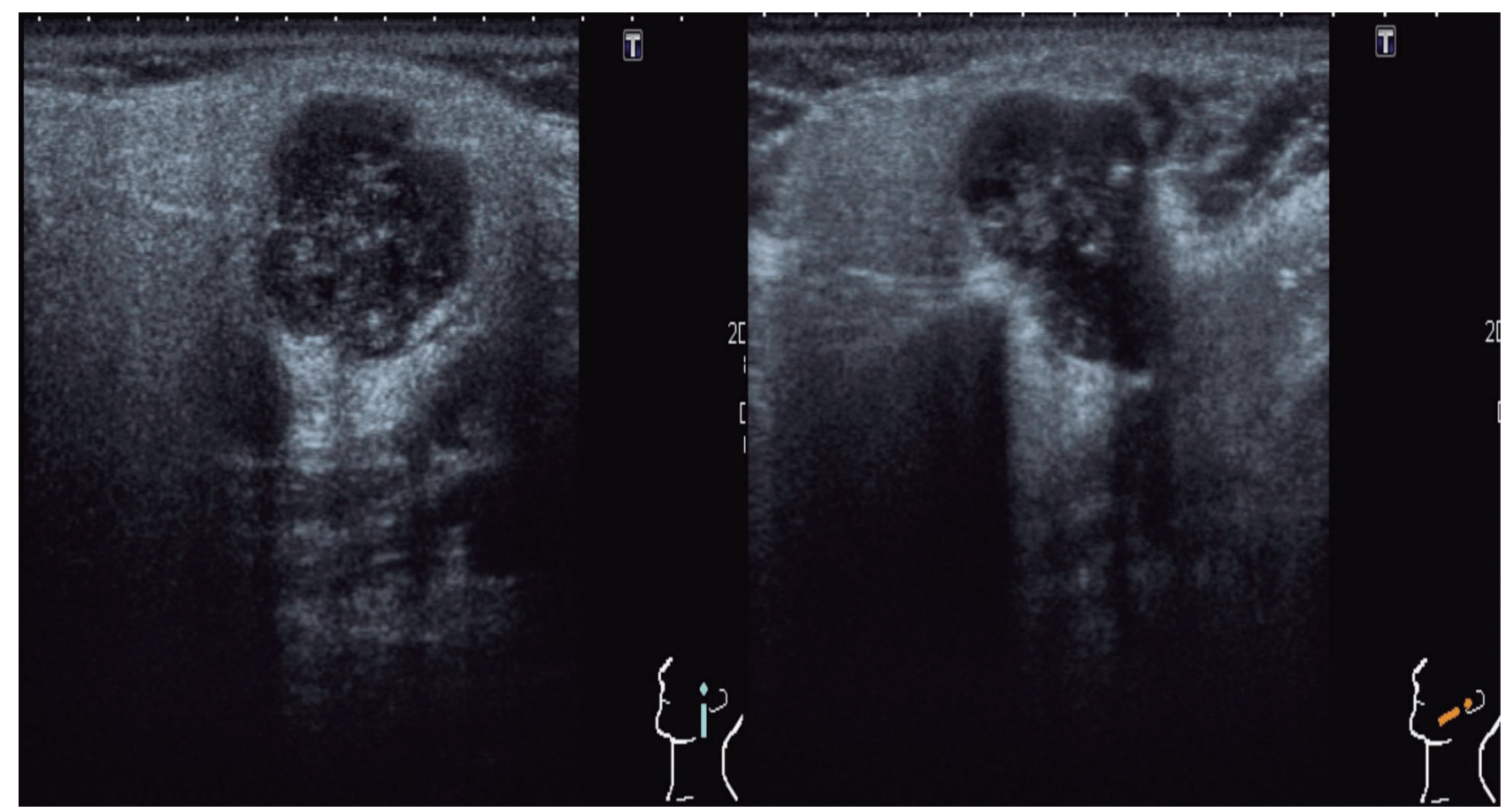

Figura 2. Corte ecográfico longitudinal y transversal de la glándula parótida izquierda
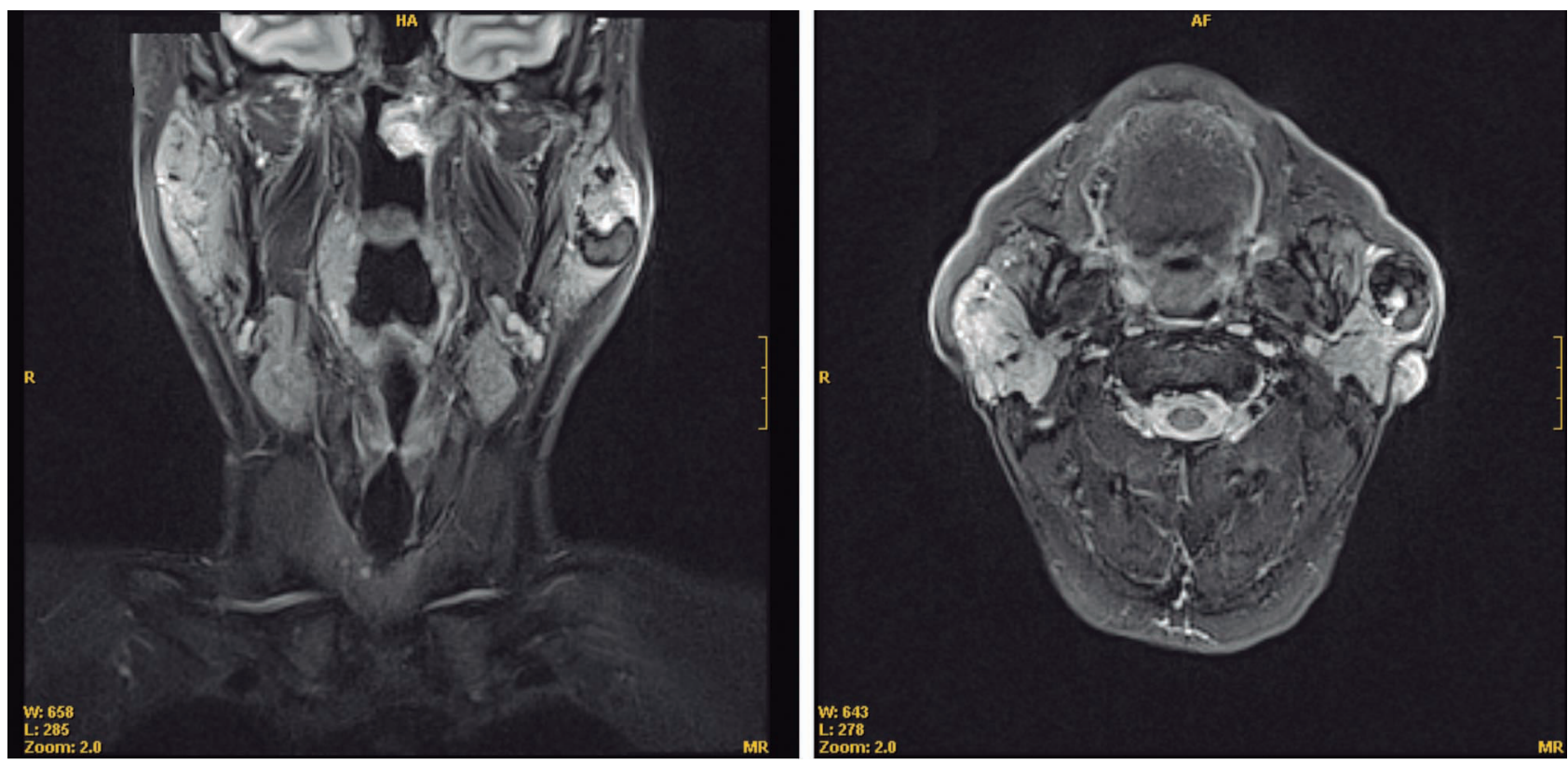

Figura 3. Resonancia magnética con imágenes compatibles con tumor de Warthin multicéntrico y bilateral

El paciente se encuentra pendiente de ser intervenido por el servicio de cirugía maxilofacial de un tumor de Warthin multifocal y bilateral.

\section{DISCUSIÓN}

El caso que presentamos es interesante por dos motivos: primero, por lo poco común de la presen- tación; y segundo, porque su diagnóstico se ha realizado en la consulta de atención primaria utilizando técnicas al alcance, hoy en día, de cualquier médico de familia.

Los tumores de las glándulas salivales bilaterales son poco habituales; representan el 1,1\% de las lesiones de las glándulas salivales mayores, y solo el $0,7 \%$ de las de la glándula parótida. El primer problema práctico que nos encontramos cuando 
estamos frente a estas lesiones es distinguir si son benignas o malignas (tres de cada cuatro lesiones en las parótidas son benignas) ${ }^{1}$, cosa casi imposible desde el punto de vista clínico. Las tumoraciones parotídeas no presentan síntomas de alarma, y es el aumento lento y progresivo del tamaño glandular lo que hace consultar al paciente.

El tumor de Warthin es el tumor parotídeo multifocal más común, y solo en un 6 a $10 \%$ de los casos es bilateral ${ }^{3}$.

En Europa y Asia el primer método diagnóstico empleado en el abordaje de las masas parotídeas es la ecografía. Aunque puede presentar algunas limitaciones, por lo general identifica con claridad las características morfológicas y vasculares (empleando el color y el Doppler) de los tumores que asientan en las glándulas salivales. No existen datos ecográficos patognomónicos para cada tumor, pero sí que en algunos de ellos pueden orientar el diagnóstico de sospecha ${ }^{4,6}$. Así, el adenoma pleomorfo está bien delimitado, tiene bordes lobulados, es hipoecoico, con refuerzo acústico posterior y pobremente vascularizado, mientras que el tumor de Whartin puede tener contenido quístico y estar muy vascularizado ${ }^{4,6}$.

En el caso que nos ocupa, las alteraciones ecográficas detectadas, sobre todo en la glándula izquierda, podrían recordar más a un adenoma pleomorfo que a un tumor de Whartin, pero aquellos nunca son bilaterales. Por eso, en la inmensa mayoría de los casos es necesario el complemento diagnóstico de la PAAF, aunque en un porcentaje no determinado de casos el diagnóstico no se obtiene hasta realizar el examen histológico de la pieza quirúrgica.

El empleo de la ecografía y de la PAAF para las lesiones de las glándulas salivales es ampliamen- te aceptado porque son procedimientos seguros y rápidos ${ }^{4,6,7}$. Ambas técnicas pueden ser realizadas con garantías en las consultas de atención primaria porque, como hemos dicho, son seguras y ofrecen una alta especificidad y precisión en la detección de estos tumores, enmarcando las patologías según su grado de severidad y consiguiendo una disminución del tiempo de espera para el paciente y una mayor eficiencia en el trabajo del médico de familia.

\section{BIBLIOGRAFÍA}

1. Brockstein BE, Brizel DM, Deschler DG. FACS. UpToDate. Last updated: 20-02 2013. (13 páginas) [citado 15-012014]. Disponible en: http://uptodate.sescam.csinet.es/ contents/salivary-gland-tumors-epidemiology-diagnosisevaluation-and-staging?source=searchresult \&search=wart hin\&selectedTitle=1 17.

2. Taylor TR, Cozens NJ, Robinson I. Warthin's tumour: a retrospective case series. Br J Radiol. 2009; 82 (983): 916-9.

3. Chulam TC, Noronha Francisco AL, Goncalves Filho J, Pinto Alves CA, Kowalski LP. Warthin's tumour of the parotid gland: our experience. Acta Otorhinolaryngol Ital. 2013; 33 (6): 393-7.

4. Huang YT, Jung SM, Ko SF, Chen YL, Chan SC, Wu EH, et al. Diagnostic Efficacy of Ultrasonography-Guided Fine Needle Aspiration Biopsy in Evaluating Salivary Gland Malignancy. Chang Gung Med J. 2012; 35 (1): 62-9.

5. Viveros Añorbe LM, Sánchez Marle JF. Tumor de Warhtin. Reporte de un caso bilateral. An Med Asoc Med Hosp ABC. 2001; 46 (2): 88-91.

6. El-Khateeb SM, Abou-Khalaf AE, Farid MM, Nassef MA. A prospective study of three diagnostic sonographic methods in differentiation between benign and malignant salivary gland tumours. Dentomaxillofac Radiol. 2011; 40 (8): 476-85.

7. Kanekar SG, Mannion K, Zacharia T, Showalter M. Parotid Space: Anatomic Imaging. Otolaryngol Clin North Am. 2012; 45 (6): 1253-72. 